\title{
Commonplace
}

\section{Things with Quartz, a platform cooperative}

Elena Martínez, Evgeniya Lupova-Henry, Elena Pérez Tirador, Tatiana Nazarova, Ámbar Tenorio-Fornés

Published on: Jan 31, 2022

DOI: $10.21428 / 6 \mathrm{ffd} 8432.8 \mathrm{~d} 0 \mathrm{cc} 8 \mathrm{c} 3$

License: Creative Commons Attribution 4.0 International License (CC-BY 4.0). 
A project of Decentralized Science, Quartz OA is an ecosystem that facilitates exchanges of resources and funding among the open access community members. It is a new cooperative economy and a new channel to fund and support independent open access publishing. Here they share the thing's they've been thinking about and are regenerated by!

\section{1/ Birds on the head}

by Elena Martínez, Product Design on Quartz Open Access \& $\underline{\text { P2P Models }}$

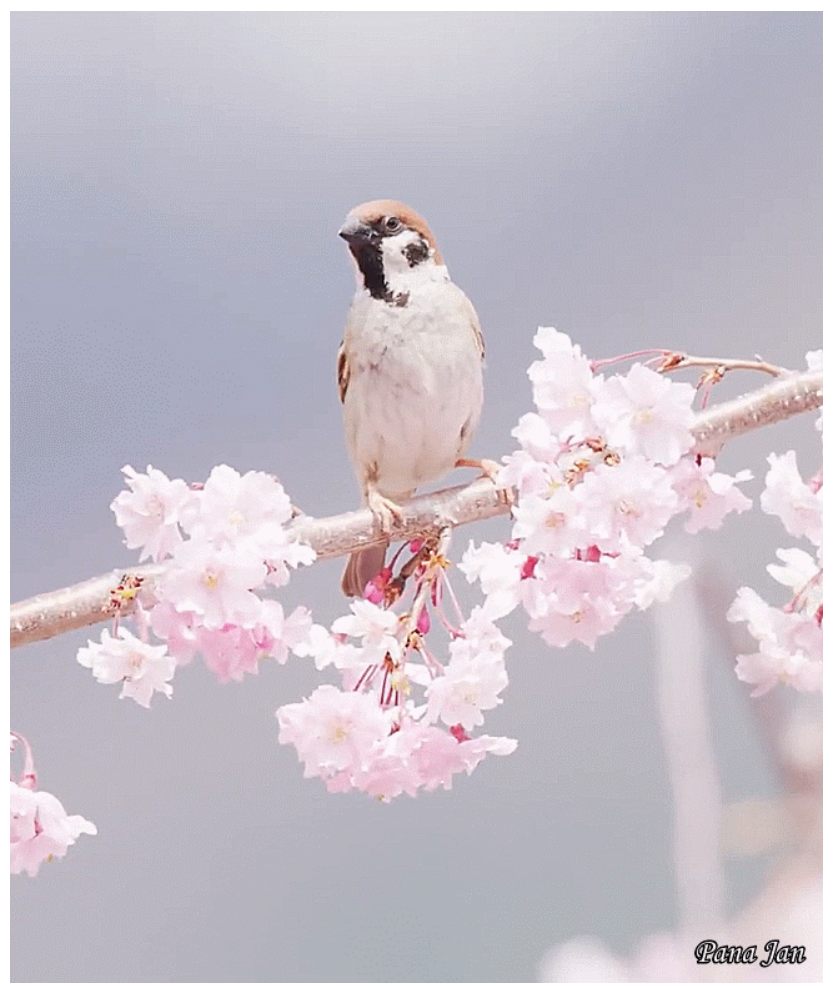

As a mother and person who works remotely, my daily activity ranges from the care that a 3-year-old child should receive - that is endless - to the work I make in front of a screen. All very domestic, very indoor. Better not to talk about pandemics. When I have some free time, I scroll through whatever, sitting on the couch because I am too exhausted to think about anything else.

With the arrival of the new year, one of my resolutions, as usual, has been to read more. And lucky me, I've started reading Jenny Odell. In her book, "How to do nothing" she talks about the attention economy and how the big internet corporations and capitalism are stealing our brains. And I couldn't agree more with her. I usually don't feel good when I pass too much time in front of screens. The lack of context and bodies 
reduces our capacity to empathize, and conversation or interactions often become cold, rude and rough. On the other hand, I began to write a diary to recover my attention and my days, which typically do not differ much from each other thanks to the pandemic and breeding. And I have realized that my best moments of joy have to do with situations of maximum presence, sensations, or real interactions: bathing in the sea, feeling the sunbeams of spring, being tickled by my son, or sharing food with friends. Moments of stillness, of looking up from the screen.

One of Jenny's habits is to watch birds in nature or in public spaces reconnect with herself, to recognize the songs and sounds they produce, or to learn about their behavior. I love this metaphor and remember it every time I feel screen anxiety. When spring finally arrives in my city, I will take a daily break to observe the bright colors of nature, grab a blanket and go to my nearest park to lie down and pass my time watching the shape of the clouds. And that will be from now my personal war against capitalism. Simple, effective, and free.

Visit the web version of this article to view interactive content. Jenny Odell, How to Do Nothing - XOXO Festival (2019)

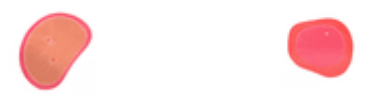

\section{2/ Books, pandemics, and Zen}

By Evgeniya Lupova-Henry, Strategy and Research manager at Quartz OA; Lecturer at the University of Applied Sciences Utrecht.

I've been dreaming about opening my own bookshop for some time now. The closest I've got to it is amassing a certain number of books and, recently, adding to my collection Ross King's "The Bookseller of Florence". I must confess, I have bought it because I was (kind of) expecting that it may offer some guidance to a budding bookshop owner. Well, it does not... unsurprisingly, perhaps! It speaks about the period of Renaissance in Florence and the role of booksellers, bookbinders, scribes and intellectuals in the dissemination of knowledge and the preservation of ancient texts by Aristotle, Cicero, Plato, Homer and many others. I must also confess that I was a bit disappointed at first not finding a 'How to' guide I was hoping for! But I kept reading... and I keep coming back to the book every day as it turned out to be a fascinating read. 
Three things in particular struck a chord with me - in a way that I did not expect - and that I want to share in this post.

First, in the 1300s parchment - animal skin - was the most common book material in Europe. Producing a large volume, such as the Bible, could require skins of up to 200 goats or sheep. So, the book production really depended on the meat-eating habits of the local populations, which meant that there was a lack of parchment whenever people ate less meat (during Lent, for example). The two other insights are related to the spread of paper. In Europe, paper was most commonly made of cotton rags which meant that the availability of material, again, was sometimes an issue (fast fashion was not there yet!). However, 2 factors contributed to the availability of rags in the 1300s1400s: increasing urbanisation and the Black Death. Urbanisation meant that people moving into cities abandoned their habits of wearing nothing under their trousers (a thing common in villages of that time) and started using underwear that then provided a ready source of rags for paper. And the Black Death... well, it wiped out a large part of Europe's population meaning that a huge surplus of clothes of the dead was turned into paper.

These 3 facts struck a chord because, for me, they all are a demonstration of how any event can have unpredictable - both positive and negative - consequences. Eating animals and urbanisation are now often seen negatively as factors contributing to climate change, for example. And there is hardly any need to mention the negative side of people dying during pandemics... But these same factors contributed to the dissemination of knowledge in the 1300-1400s in Florence and, to an extent, made us who we are now. Nothing is 'good' or 'bad' per se. It's something I 'know' but often forget when the avalanche of 'bad' news covers me whenever I open my inbox or social media feed. So, to finish this post (that turned out rather long!), I want to share this video illustration of the Chinese parable told by Alan Watts (British philosopher that popularized Eastern philosophy in the West) to illustrate his point about liberation and empowerment of not categorising everything into good or bad, gain or loss:

\section{Visit the web version of this article to view interactive content.}

\section{The Story of the Chinese Farmer}

P.S. I came across the video in The Marginalian newsletter that is like a breath of fresh air for those who sometimes feel overwhelmed by the 'bad' news in their inboxes! 


\section{3/ Learning weird programming languages}

by Elena Pérez Tirador, Blockchain and Front End Developer at Quartz OA.

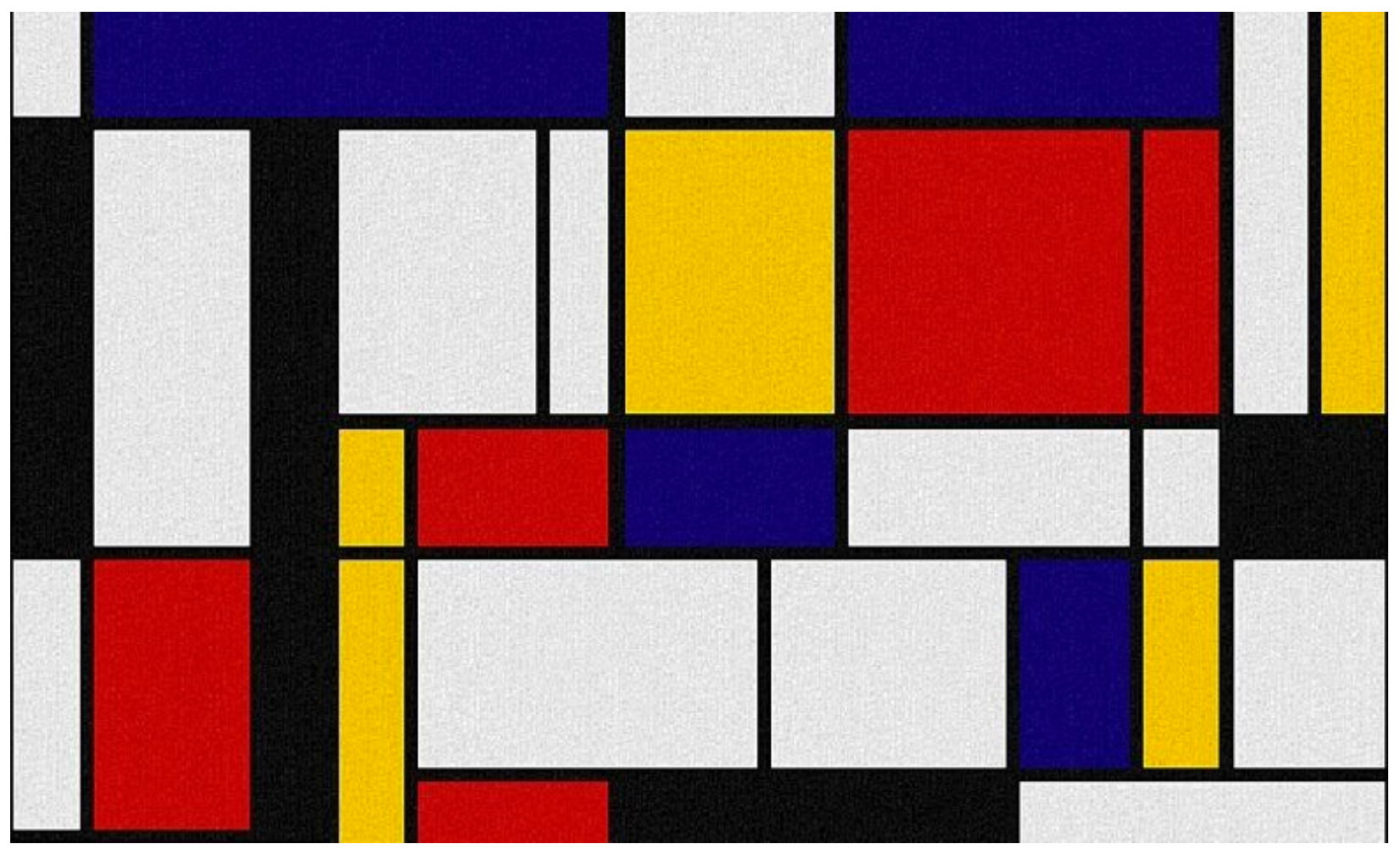

Programming is part of my job. But it has also always been one of my hobbies. It opens so many opportunities and lets you create and express yourself in different ways. For me it feels like a never-ending field of possibilities.

There are so many different programming languages, and each of them serves a different purpose: some of them are better for creating programs and applications for any user to use, others are best for creating new operating systems, others are used for mathematical calculations... you name it. As a programmer, you usually learn how to use several programming languages, and then start adapting to the new circumstances. And usually this adaptation involves learning new languages and even new ways of thinking. And sometimes you just want to learn new things for the sake of learning, just because it's fun! I find myself in that spot somewhat frequently, where I 
want to learn a new programming language, either for work or for some personal project.

Some years ago, I found this really cool website called "Learn X in Y minutes." It contains a list with multiple programming languages, and for each of them a simple tutorial explaining the basics of the language. This tutorials are created by the community and the list keeps growing with the years. The explanations are simple and to-the-point, and can help you get the hang of a language in minutes.

A fun thing to do is just scroll through the languages, pick one at random and learn a bit about it. And you might even find some surprises in the process... like one of the so called "esoteric languages". Which are programming languages designed, not for their utility or efficiency, but for their stetic properties or just for fun. For example, LOLCODE, a language based on the cat memes from the 2010's.

But esoteric languages can go way further than that. There are things like Malbolge, a language designed to be the most difficult programming language ever created, where even the simplest program becomes a convoluted mess, or Piet (inspired by Piet Mondrian), a language where the programs are bitmaps, images that resemble abstract art pieces. Or, my favorite, Shakespeare, where programs are written in the form of Shakespearean plays where the characters insult or flatter one another.

So.. who said programming could not be a form of art? :)

\section{4/ How mini habits made me read again.}

By Tatiana Nazarova, UI and Graphic designer.

During the quarantine, I tried to be optimistic. I thought, ok, I will make the best out of this situation. Now that I'm always at home I'll have time for sports, reading, and painting, finally! I tried to buy dumbbells for a month, apparently, everybody decided to train, I prepared books that I wanted to read and my art materials. Since then almost two years have passed, a lot has happened, but books have not been read and the dumbbells are still in the unpacked box. 
Recently I decided that I need to stop procrastinating and start doing something about it. I realized that I hadn't read a single book this year. When I first heard about 2 minutes habits, I thought it was stupid.

The Two-Minute Rule states "When you start a new habit, it should take less than two minutes to do."

What can be done in 1-2 minutes? What do you mean the result is not important? But then I decided to give it a chance. Before going to bed, I decided to read two pages. No matter how tired I am, no matter what time I go to bed, just do it. And I got involved. I don't force myself anymore, I enjoy it. It turned out that in 2 minutes you actually can do things, for example, you can draw a great sketch.

I am at the begging of my way, but it works. So I'm going to unpack the dumbbells, it just takes two minutes.

Here you have 11 minute's video about "The 1-minute secret to forming a new habit"

Visit the web version of this article to view interactive content.

Christine Carter: The 1-minute secret to forming a new habit | TED

\section{5/ Live Coding}

By Ámbar Tenorio Fornés, Decentralized Governance and Lead Developer at Quartz OA

This text was produced live, while coding some music. See the video:

Visit the web version of this article to view interactive content.

\section{Live Coding - a fun thing to do}

Programming music is one of the things I do for fun! It is as easy as writing some simple commands, such as

p1 > play('V')

and the music starts playing! 
We can also make some changes to the code to change the music, play other sounds, change the duration of the notes, and their pitches, and even add some cool effects.

This is what we call LIVE CODING. Live performances of this type of music are called Algoraves, from Algorithmic Raves. Often they include projections of the code that is producing the music.

One of the key values of Algoraves is DIVERSITY. That is why I am showing how easy it is to start making some electronic music with it.

Hopefully, some of you will be inspired and try live coding. Perhaps, you will even organize, or at least join the next algorave at your city.

NOTE: The programming language I am using to code this music is FoxDot. www.foxdot.org.

And the most difficult thing is to stop playing with it. 